\title{
AVERSÃO À TEORIA E INDIGÊNCIA DA PRÁTICA: CRÍTICA A PARTIR DA FILOSOFIA DE ADORNO
}

\author{
ROBSON LOUREIRO
}

\begin{abstract}
RESUMO: Na educação, o pragmatismo tornou-se capilar e infiltra desde a formação docente até as definições do que e como ensinar. Buscamos evidenciar as contribuições de Adorno para o confronto dessa perspectiva filosófica. A vitalidade de suas análises está em se dirigir ao núcleo característico da tradição pragmática. Para ele, na sociedade administrada, a formação cultural se converte em semiformação. $\mathrm{O}$ espírito pragmático instaura a racionalidade do sempreigual na relação sujeito e objeto, teoria e prática e alimenta o fenômeno da aversão à teoria. Configuram-se assim facetas da miséria da formação cultural contemporânea: a atrofia do pensar autônomo e a indigência da prática. Porém, o filósofo vê a possibilidade de um pensamento de resistência, que não abre mão de seu referente objetivo e da validade objetiva da verdade, opondo-se à ruína da razão. A experiência reflexiva criadora e criativa no/sobre o trabalho educativo não pode se desviar desse pensamento não eficaz.
\end{abstract}

Palavras-chave: Adorno. Teoria crítica e educação. Tradição pragmática. Relação teoria e prática.

\section{AVERSION TO THEORY AND POVERTY OF PRACTICE: CRITICISM BASED ON ADORNO's PHILOSOPHY}

ABSTRACT: In education, pragmatism has become widely spread and it pervades everything from teacher training to the definitions of what and how to teach. We seek to highlight Adorno's contributions to face this philosophical trend. The vitality of his analyses rests in the fact he addresses the core of the pragmatic tradition. He denounced how, in the administered society, the cultural formation has become semi-formation. The pragmatic spirit establishes the "always the

Doutor em Educação e professor adjunto do Centro de Educação da Universidade Federal do Espírito Santo (UFES).E-mail: robbsonn@uol.com.br 
same" rationality in the relationship between subject and object, theory and practice, and feeds the phenomenon of aversion to theory, characterised by the atrophy of the autonomous thinking and the poverty of practice. However Adorno sees the possibility of a resistance thinking that does not renounce to the objective referent and objective value of truth but is opposed to the collapse of reason. The reflexive experience in / on the educational work cannot depart from this thinking.

Key words: Adorno. Critical theory and education. Pragmatic tradition. Relation theory and practice.

\section{Introdução}

D

esconfiado da rebeldia de seu subordinado e na esperança de persuadi-lo da grandeza de seu ofício, o capitão Beatty explica ao policial bombeiro Montag o momento em que sua profissão deixa de ter como objetivo combater incêndios e passa, então, a incinerar livros. ${ }^{1}$ A queima de livros acontece em uma sociedade na qual a leitura da escrita é desprezada e combatida. Beatty se lembra de quando isso começou. Observa que muito foi feito "até a fotografia chegar à maioridade. Depois, foi o cinema (...) no começo do século XX. O rádio. A televisão. As coisas começaram a ter massa. E, como tinham massa, tornaram-se mais simples" (Bradbury, s/d, p. 67). Os mass media, explica o capitão, fazem a cabeça girar tão depressa que expelem para longe todos os pensamentos desnecessários que consomem tempo. Com isso, o sistema educacional passou por mudanças: reduziu-se a escolaridade, deixou-se de lado a disciplina, abandonaram-se as filosofias, a história, as línguas, esqueceram-se quase por completo a gramática e a sintaxe. Se não se quer que uma pessoa seja politicamente infeliz, enfatiza o capitão, é preciso não lhe dar os dois lados de uma questão para se preocupar. $\mathrm{O}$ melhor é não dar nenhum lado da questão. O melhor é esquecer a existência da guerra, por exemplo. Se há ineficiência por parte do governo, se ele é autoritário e perdulário,

(...) é melhor ser tudo isso sem que as pessoas se preocupem com essas coisas. Paz, Montag. Dê às pessoas concursos que elas ganham lembrando-se das letras de cançôes mais populares, dos nomes das capitais ou do Estado que produz mais petróleo. É melhor entulhá-las de dados não combustíveis, entupi-las com tantas "informaçōes" que elas se sintam enfastiadas, mas 
muitíssimo "brilhantes". Aí elas acham que estão pensando, ficam com uma impressão de estar em movimento sem se mexer. E ficarão felizes porque os fatos dessa espécie não se modificam. Não lhes dê coisas escorregadias como filosofia ou sociologia para embrulhar as coisas. Esse é o caminho da melancolia. (Bradbury, s/d, p. 74)

Esse é apenas um trecho do romance Fahrenheit 451, escrito por Ray Bradbury (s/d) à sombra do pós-Segunda Guerra Mundial. ${ }^{2}$ Por um lado, ele condensa, em termos literários, angústias de seu tempo: os horrores da guerra, as experiências totalitárias e, principalmente, a danificação da formação cultural com a proliferação dos mass media. Por outro, ousa delinear movimentos de resistência corporificados nas pessoas-livro (book-people): uma quase distopia, ainda com um telos de credulidade nas mudanças.

A sociedade atual não é a mesma da retratada no romance. Contudo, não deixam de ser surpreendentes algumas de suas aproximações: a desvalorização da cultura escrita; a hegemonia do espetáculo e o enaltecimento do pensamento do clichê pelos diversos mecanismos da indústria cultural, que tecem loas às práticas sociais relacionadas à pragmática lógica do sistema de trocas.

Fahrenheit 451 também instiga a pensar como determinados processos da vida social não só perduraram, mas se intensificaram ao longo das últimas décadas. Um deles diz respeito à hegemonia de tendências pragmáticas nos âmbitos da política (Araújo, 2004; Benjamin, 2003), da militância sindical (Alves, 2000), da filosofia (Rorty, 1994), entre outros. No campo educacional, a forma pragmática de pensar e agir tornou-se capilar e infiltra desde a formação docente, a filosofia da educação até definições do que e como ensinar. Essa hegemonia não só expressa a submissão ampliada da vida social à lógica e aos ditames da racionalidade técnica característica do capitalismo contemporâneo, mas também alimenta facetas do atual processo de danificação cultural.

Este artigo tem como escopo evidenciar as possíveis contribuições do filósofo alemão Theodor Adorno para a crítica dessa tendência pragmática que impregna o debate e a prática educacional atual. Inicialmente, esboçamos alguns aspectos da vinculação entre o pragmatismo de John Dewey (a quem Adorno dirigiu sua crítica) e o de Richard Rorty, principal representante da versão neopragmática. Em seguida, retomamos algumas reflexões de Adorno sobre o pragmatismo, 
tendo como eixo a relação entre teoria e prática, e sobre facetas do pensar filosófico que se contrapõe à forma pragmática de pensar e agir. Sustentamos que as críticas adornianas à tendência pragmática em seu tempo podem inspirar a pesquisa educacional a combater o pragmatismo contemporâneo.

\section{Notas sobre pragmatismo e neopragmatismo}

Tratar as convergências e diferenças da filosofia de dois pensadores como Dewey e Rorty, por si só, constitui um plano de estudo vasto e impossível de ser sistematizado, de forma minuciosa, nos limites deste artigo. Contudo, para avaliarmos as possíveis contribuições de Adorno para a crítica do pragmatismo contemporâneo na educação, parece-nos incontornável a tarefa de esboçar alguns caminhos para estabelecer o diálogo entre esses dois intelectuais.

Como lembra Ghiraldelli Jr. (1998, p. 42), com o termo experiência, os velhos pragmatistas indicavam a interação contingente do ser humano com o seu ambiente: "O que se sabe delas [dessas interaçôes] é que, depois que elas ocorrem, o homem parece conseguir lidar melhor com outras experiências, talvez venha a conseguir maior previsibilidade e controle sobre as coisas que o cercam".

No lugar de sujeito e objeto, a experiência coloca a relação contingente e não-teleológica entre o ser humano e o meio, na qual o agir sobre algo sempre implica sofrer as conseqüências dessa ação. Por isso, para Dewey (1916, cap. 11), a experiência conecta um elemento ativo e passivo: ela envolve a ação de um agente que, por sua vez, recebe as conseqüências reativas do meio sobre ele. Dewey acredita que, em uma combinação peculiar, esses elementos impulsionam transformaçôes e aprendizagens. Nesse sentido, a experiência é uma ocupação ativo-passiva e não, originariamente, cognitiva; ela é constituída de causas e efeitos, atividade e conseqüências. A educação, em Dewey (1916, cap. 11), constitui-se no processo de compartilhar experiências por meio da comunicação.

Por um lado, a concepção deweyana de experiência representa uma reação à noção de verdade como representação, pois remete para a impossibilidade de o ser humano perceber e compreender o mundo fora da experiência, de haver consciência separada das interações nas quais ela sempre se encontra. Aniquila-se, aqui, qualquer chance de se 
Aversão à teoria e indigência da prática: crítica a partir da filosofia de Adorno

referir a uma realidade existente em-si ou de um intelecto puro. O mundo é sempre o que aparece para-nós na experiência.

Por outro lado, ao chamar sua própria filosofia de instrumentalismo, Dewey indicava que uma idéia é um instrumento para resolver problemas; ela não é verdadeira ou falsa, mas sim eficaz ou não. Nesse sentido, "Pensar é o estabelecimento exato e deliberado de conexões entre o que é feito e suas conseqüências" (Dewey, 1916, cap. 11, s/p.). Portanto, a função do pensamento é descobrir as conexões entre nossa atividade e os efeitos que dela decorrem. Dessa forma, pode-se estruturar e organizar a experiência na direção de resultados desejáveis, ou seja, antecipar as conseqüências. A partir desse argumento, percebe-se que, no próprio coração do tema da verdade, encontra-se a noção de experiência. Um enunciado não aponta as propriedades essenciais de um objeto, mas as condições contextuais de seu uso e aplicabilidade.

Rorty (1999) não esconde sua admiração por Dewey, em especial, por entender que seu mestre sustentava, com a noção de experiência, uma postura anticartesiana, antiessencialista e antirepresentacionista. Contudo, a virada lingüistica (da qual Rorty é tributário) desferiu um golpe na noção de experiência, característica da filosofia de Dewey e James, e erigiu a linguagem como tema primordial do atual pragmatismo. Este, na versão rortyana, concebe a noção de experiência como apenas mais uma história sobre a vida do homem, mais uma descrição que pode até melhorar a nossa lida com o meio (Ghiraldelli Jr., 1998).

Pode-se admitir que o pensamento rortyano preserva, da idéia deweyana de experiência, o seu caráter incontornável e inelutável, mas o compreende em termos lingüísticos. A linguagem se torna o horizonte de toda ação humana; pretender referir-se a algo em-si equivaleria, no pensamento neopragmático, à missão impossível de pular sobre a própria sombra.

Rorty (1999) considera a linguagem um instrumento, uma ferramenta para o homem conseguir o que quer. Em termos ontológicos, Rorty não chega a negar a existência da realidade, mas nega a possibilidade de a ela ter acesso fora do âmbito de descrições particulares: “(...) o caráter de qualquer coisa é relativo à escolha de uma descrição (...)” (p. 17).

Por sua vez, essas descrições não são verdadeiras ou falsas, mas úteis ou não. Portanto, a verdade é sempre "realidade-sob-uma-certadescrição" (Rorty, 1994, p. 370) e, dessa forma, deriva de acordos 
intersubjetivos em contextos locais e se volta para uma lida bem-sucedida com o meio. ${ }^{3}$

A educação, para Rorty (1994, p. 359), tem que partir da aculturação, ou seja, "(...) descobrir bastante sobre as descrições do mundo oferecidas por nossa cultura (...)”, estar em conformidade com normas discursivas e convençôes locais. Rorty (ibid., p. 353) assevera: "Do ponto de vista educacional, enquanto oposto ao epistemológico ou tecnológico, o modo como as coisas são ditas é mais importante do que a posse de verdades".

Em termos educacionais, Hendley (1998) considera a posição de Rorty distante da de Dewey, que não somente conferia um papel central à educação a ponto de considerar a filosofia uma teoria geral da educação (Dewey, 1916, cap. 25, s/p), mas possuía uma intervenção significativa no campo pedagógico. Além disso, esse autor lembra que a proposição rortyana de níveis distintos de escolaridade com projetos educacionais distintos (o nível inicial com um mínimo de questionamento e o superior orientado pela liberdade acadêmica, pela dúvida e crítica social) é um exemplo básico de dualismo em educação que Dewey rejeita. Assim, para Hendley, ao contrário do que se pensa comumente, Rorty não seria um discípulo tão fiel de Dewey.

\section{Semiformação e a aversão à teoria}

A aversão à teoria, característica de nossa época, seu atrofiamento de modo nenhum casual, sua proscrição pela impaciência que pretende transformar o mundo sem interpretá-lo, enquanto, em seu devido contexto, afirmavase que os filósofos até então tinham apenas interpretado - tal aversão à teoria constitui a fragilidade da práxis. (Adorno, 1995a, p. 211)

A crítica adorniana ao pragmatismo vincula-se eminentemente à análise histórica de absolutização da faceta instrumental da razão com o advento da sociedade capitalista e, em especial, com a sua configuração contemporânea, marcada pela expansão da lógica da mercantilização da cultura, sintetizada no termo indústria cultural.

Apesar de suas promessas originariamente emancipatórias, a racionalidade burguesa submeteu-se à execução dos interesses do capital. A razão burguesa passou a subsidiar as relações capitalistas vigentes na aparelhagem econômica global. O preço que pagou foi a subserviente 
Aversão à teoria e indigência da prática: crítica a partir da filosofia de Adorno

subordinação da razão ao imediatamente dado (Adorno \& Horkheimer, 1985, p. 38). O pensamento tornou-se cativo da imediaticidade e dos imperativos pragmáticos de lucro e exploração capitalista. Dessa forma, no triunfo da dimensão instrumental da razão, muitas vezes festejado como símbolo do progresso,

O que não se diz é que o terreno no qual a técnica conquista seu poder sobre a sociedade é o poder que os economicamente mais fortes exercem sobre a sociedade. A racionalidade técnica hoje é a racionalidade da própria dominação. Ela é o caráter compulsivo da sociedade alienada de si mesma. (Idem, ibid., p. 114)

O pensamento, abandonado e coisificado, reage sobre aqueles que o esqueceram. Com isso, o Esclarecimento desiste de sua própria realização e se converte em enganação das massas. Porém, observam Adorno e Horkheimer, essa enganação não acontece quando a indústria cultural manipula as distrações. O enganar está no fato de que tal indústria perverte o prazer e permanece voluntariamente ligada aos clichês da cultura em processo de liquidação. Ou seja, "A indústria cultural fornece como paraíso a mesma vida cotidiana" (Adorno \& Horkheimer, 2002, p. 40), dilacerada e danificada. Nesse contexto, a promessa de uma formação humana emancipada e esclarecida se esvai.

Os sintomas do colapso da formação cultural, observados por toda parte, mesmo no meio de pessoas tidas como cultas, não se esgotam com as insuficiências do sistema educativo e dos métodos de educação criticados por gerações. $\mathrm{O}$ comum é estabelecer uma relação direta e mecânica entre bens culturais e civilização. No entanto, Adorno (1992) afirma ser necessário dessacralizar a própria idéia de cultura, pois ele recorda que muitas pessoas tidas como cultas apoiaram o nacional-socialismo.

Tal fato o faz pensar que a formação (Bildung) tem como fim tornar os indivíduos aptos a se afirmarem como racionais em uma sociedade racional e a existirem como seres livres em uma sociedade livre. No entanto, a Bildung $g^{4}$ é ambígua, pois nela o indivíduo tanto se adapta à realidade social, reforçando e reproduzindo o mundo que o danifica, como também pode resistir à adaptação cega, ahistórica e sem compromisso com a auto-reflexão crítica. A prevalência de uma formação cultural unilateral, de acomodação ao existente que se esquece que "seu sentido próprio não pode se separar da implantação das coisas humanas" (Adorno, 1992, p. 32), promove uma formação regressiva ou, o que Adorno chama, de semiformação. ${ }^{5}$ Apesar de toda ilustração e 
informação que se difundem, a formação cultural na sociedade administrada se converte em semiformação.

Adorno (1992) observa que o sonho de formação cultural, que impõe a libertação da imposição dos meios, bem como da estúpida e mesquinha utilidade, transforma-se em apologia do mundo administrado. ${ }^{6}$

A semiformação não significa formação pela metade que, para se tornar plena, bastaria ser complementada: "o entendido e experimentado medianamente - semi-entendido e semi-experimentado - não constitui o grau elementar da formação, e sim seu inimigo mortal" (Adorno, 1992, p. 48). A semiformação também não é mera ausência de cultura. Como argumenta Duarte (2003, p. 445), ela é o resultado de um elaborado processo de destruição das "possibilidades libertadoras até mesmo da incultura, a qual 'poderia ser aumentada em consciência crítica graças a seu potencial de dúvida, chiste e ironia”". Assim, para esse autor, a semiformação está além da ingenuidade, ela é o corolário “(...) de uma exploração consciente do estado de ignorância, de vacuidade do espírito - reduzido a mero meio -, surgida com a perda de tradição pelo desencantamento do mundo e é totalmente incompatível com a cultura no sentido estrito" (Duarte, 2003, p. 445).

As pessoas tranqüilizam-se e até se orgulham do aparente enriquecimento cultural. Contudo, não desconfiam que, em verdade, pouco ou quase nada sabem daquilo que consomem. O que impera no indivíduo semiformado é o pensamento vazio sobre a capacidade de julgamento crítico. Esse império produz um recorrente incentivo a não reflexão.

Para Adorno (1995a, p. 204), "O espírito burguês reúne a autonomia e a aversão pragmatista pela teoria tão antinomicamente quanto a sociedade que o sustenta”. A versão filosófica da lógica pragmática disseminada a partir do instrumentalismo burguês é tomada como foco de apreciação por Adorno (1995a). Ele tem como alvo o pragmatismo de Dewey que, motivado pela ênfase na utilidade, advoga a unidade imediata entre teoria e prática, ou melhor, a subsunção da teoria à prática imediata.

No entanto, essa unidade entre teoria e prática não seria um avanço diante de teorias supostamente desvinculadas da realidade social? Ela não seria uma meta desejável e a ser perseguida? Não é esse o argumento que tantas vezes se ouve, por exemplo, no campo da educação: que as teorias pedagógicas devem oferecer uma resposta imediata e rápida aos problemas da prática social? 
Na perspectiva adorniana, esse apelo pragmático à identidade entre teoria e prática traduz e, ao mesmo tempo, fomenta os mecanismos constituintes da indústria cultural. Para explicar isso, Adorno sustenta o argumento de que a unidade imediata entre teoria e prática vincula-se a uma certa relação entre sujeito e objeto. Mais precisamente, essa unidade implica, no plano social, a coisificação do sujeito em face dos objetos/ mercadorias culturais.

Para a Teoria Crítica, a indústria cultural expressa a dinâmica da mercantilização da cultura na sociedade capitalista avançada, na qual a indústria e a racionalidade da produção modificam o processo de criação cultural e conferem uma homogeneidade de padrão que perpassa diferentes veículos culturais. A cultura contemporânea, afirmam Adorno e Horkheimer (1985), a tudo confere um ar de semelhança. Dito de outra forma, toda cultura de massa é idêntica.

No procedimento da indústria cultural, seus produtos, mecanicamente diferenciados, aparecem sempre como a mesma coisa. Assim, a repetição é um traço de seu funcionamento. Suas inovações típicas são intrínsecas ao sistema.

Como explicar essa padronização? As respostas fáceis atribuem a origem desse processo às necessidades supostamente espontâneas dos consumidores. Isso explicaria porque estes aceitam essa padronização sem resistência. A produção em massa nada mais faria que democratizar o acesso aos bens culturais (Adorno \& Horkheimer, 1985). Contudo, o que é visto como espontaneidade dos consumidores, na verdade, é imposto ao sujeito pelo esquematismo da produção. Forja-se, a priori, uma necessidade que é de tal forma introjetada e massificada que passa a ser sentida como genuína e própria das pessoas. ${ }^{7}$

Adorno (1992, p. 40) assinala que as mercadorias da indústria cultural perpetuam a hegemonia da semiformação, a onipotência do espírito alienado. Nesse sentido, elas se sobrepõem aos indivíduos. Se, no processo anímico, a coisa era dotada de alma, na sociedade industrial, as almas são coisificadas. Em outras palavras, em termos sociais, o sujeito é reificado em função do fetiche da mercadoria. Quando isso acontece, explica Adorno, o esforço do pensamento é diluído ao desde sempre dado e o sujeito é adaptado às forças sociais vigentes. $\mathrm{O}$ esforço reflexivo é abafado em detrimento da lógica pragmática da troca: a teoria se dilui diante dos interesses do lucro. Por essa razão, Adorno julga que sustentar a identidade entre teoria e prática, como o faz o pragmatismo, perpetua o princípio da dominação. 
O resultado desse processo é a derrota de uma práxis verdadeira e o engendramento da pseudo-atividade, ou seja, da prática impermeabilizada contra a teoria. Segundo Adorno (1995a, p. 217-218), a pseudo-atividade representa a despotenciação da prática, que pressupõe um agente livre e autônomo, mas anula o papel mediador do sujeito.

Adorno reconhece que o apelo pragmático da pseudo-atividade é tão sedutor e reconfortante que se infiltra mesmo em grupos e movimentos que combatem a forma de dominação capitalista. Longe de se calar diante de tal diagnóstico, ele também direciona sua crítica a vários seguimentos da tradição da esquerda política que, a seu ver, exerceram uma pseudo-atividade, expressa em um ativismo cego, apressado em fazer uma transposição direta à práxis. Para Adorno, o ativismo é repressivo, pois se recusa a reconhecer sua própria impotência: "Os que não param de gritar: Demasiado abstrato!, empenham-se num concretismo, numa imediatez, que estão abaixo do nível dos meios teóricos disponíveis. Isso favorece a práxis aparente" (Adorno, 1995a, p. 223).

Em termos sociais, a relação entre teoria e prática no pragmatismo envolve a coisificação do sujeito; porém, este é valorizado na teoria pragmática do conhecimento. Quando se avalia a verdade, o critério de utilidade vincula-se diretamente à experiência dos indivíduos, ao êxito dos resultados práticos. Essa forma de subjetivação da verdade também se preserva no neopragmatismo, para o qual a verdade é interna a um ponto de vista histórico particular e, portanto, restringe-se a uma convenção social, sendo impossível almejar um conhecimento que transcenda o contexto e os interesses locais.

Filosofia: o pensamento que resiste

(...) uma verdadeira práxis revolucionária depende da intransigência da teoria em face da inconsciência com que a sociedade deixa que o pensamento se enrijeça.

(Adorno \& Horkheimer, 1985, p. 51)

Para apreender o contraponto adorniano ao pragmatismo filosófico, privilegiamos a sua reflexão sobre a filosofia (1995a), a partir da relação teoria e prática (1995b). 
Adorno (1995a) detém-se no caráter de resistência que a filosofia pode assumir em face do mundo danificado, do qual participa e corrobora as tendências pragmáticas. $\mathrm{O}$ primeiro aspecto que chama atenção é que o autor preserva a noção de mundo objetivo em sua filosofia.

De forma insistente, Adorno (1995a) defende a dependência do pensar em relação ao seu objeto e critica o pensamento que se pretende sem referente, que se manifesta sem levar em conta sua materialidade. Um pensamento, portanto, que "(...) se afunda em si mesmo como que em uma esfera de suposta pureza" (Adorno, 1995b, p. 20). Longe de uma possível libertação, essa forma de conduzir a filosofia cumpre a função de reprimir o pensamento. A prática filosófica é reduzida a uma esfera distante de uma prática social possível.

Aqui surge uma dúvida: O pragmatismo de Dewey e o neopragmatismo de Rorty não estão de acordo com essa afirmação de Adorno? Quando instituem a experiência e a linguagem como centro de suas filosofias, esses pensadores não estariam reagindo contra uma suposta neutralidade e ratificando que valores e interesses sociais impregnam, por exemplo, o sentido de verdade? De certa forma, sim. Porém, em sua argumentação, Dewey e Rorty fazem o referente objetivo desaparecer. Como o em-si é incognoscível, seja porque não existe, seja porque é inacessível, a materialidade é liquefeita em um constructo (inter)subjetivo. A comparação suportável é sempre entre os resultados das experiências ou entre as diversas descriçóes construídas por grupos particulares.

Neste caso, o pensamento se afunda em si mesmo, não por advogar sua pureza. Ao contrário, por mostrar-se saturado de interesses, o pragmatismo de Dewey e de Rorty chega ao pensamento autoreferencial criticado por Adorno. Tal pensamento move-se em uma dinâmica de identificação entre a realidade e os modos de conhecê-la. Em sentido diverso, para Adorno, o pensar filosófico não coincide com o conteúdo pensado, apesar de ser dele dependente. Ele considera que, "tanto no conhecimento pré-filosófico quanto na filosofia, as coisas não se passam sem uma certa independência do pensar em relação à coisa mesma" (Adorno, 1995a, p. 15).

A atividade do sujeito, segundo Adorno (1995a, p. 18), "é um constituir-se do Eu a partir do não-Eu”. Isso significa que a constituição do sujeito se dá pela mediação daquilo que não lhe é idêntico, ou seja, do objeto enquanto não-ativo. A passividade do objeto inscreve-se 
no âmbito da atividade do sujeito. Eis porque Adorno afirma que a filosofia, como um pensamento produtivo e criativo, é também reativa e determinada a partir de sua coisa, pois aí reside a sua passividade.

Se, por um lado, o objeto determina o pensamento e não o contrário, por outro, o pensamento reage em face do não-idêntico e recebe em si aquilo que ele não é. De acordo com Zuin et al. (2000, p. 90-91), "como bom materialista que é, Adorno enfatiza a proeminência do objeto sobre o sujeito (...). É verdade que o objeto só pode ser pensado por meio do sujeito, mas o sujeito é impensável, até como idéia, sem o objeto". Contudo, para Adorno, o primado do objeto não significa a coisificação da consciência, pois, para se tornar possível, o conhecimento requer a mediação do sujeito racional. Nesse sentido, o fundamental da atividade filosófica é a concentração que se apresenta como momento ativo do sujeito (Adorno, 1995a, p. 18) em face da vida danificada.

Assim compreendida, a relação sujeito e objeto engendra o processo histórico. A história, em Adorno, é fruto da dialética da práxis humana, constituída na relação entre homens e mulheres e a realidade material (Buck-Morss, 1981). Por sua vez, essa dialética ganha sentido quando pensada nos moldes postos por Marx (1988), ao afirmar que o ser humano faz história não nas condições por ele escolhidas, mas naquelas dadas diretamente e herdadas do passado.

Como decorrência dessa proposição, a filosofia de Adorno provoca um tratamento diferenciado da questão da verdade, que o afasta, de forma radical, do pragmatismo. Para ele, a verdade possui um conteúdo objetivo, ou seja, histórico, que não se dobra a uma perspectiva de eficiência empírica, tampouco a um caráter meramente lingüístico.

Para sair da exacerbação da razão instrumental presente na invocação pragmática ao imediato, Adorno (1995c) argumenta que a atividade filosófica precisa se guiar pelo amor. O conceito de amor proposto distancia-se da vertente sentimentalista e moralizante comumente adotada. Para ele, a fetichização da técnica despotencializa a aptidão de as pessoas amarem (Adorno, 1995c, p. 133). Ou seja, quando as relaçôes humanas se transformam apenas em relações de troca, as pessoas e a natureza só interessam à medida que podem ser manipuladas. As pessoas “(...) são inteiramente frias e precisam negar, também em seu íntimo, a possibilidade do amor, recusando, de antemão nas outras 
pessoas o seu amor antes que o mesmo se instale. A capacidade de amar, que de alguma maneira sobrevive, eles precisam aplicá-la aos meios" (idem, ibid.).

Essa tendência dificulta ao pensamento filosófico criar as condições de possibilidades para resistir ao processo de fetichização e conseqüente danificação da formação humana.

A capacidade para amar significa profusão libidinal na relação consigo e com os outros (Adorno, 1995c, p. 133). Dessa forma, para que o pensamento filosófico assuma sua radicalidade, ele precisa se guiar pela pulsão de vida que caracteriza a conduta humana ativa e criadora.

Com as aceleradas transformações tecnológicas e a ânsia de um consumo frenético e fugaz, típicos da sociedade capitalista, o apelo à aplicação imediata da teoria sufoca a capacidade de pensar e submete a própria teoria à impaciência da prática. Por isso, para Adorno, a paciência apresenta-se como outro elemento essencial ao pensamento filosófico. Para ele, paciência não é agitação afanosa e tampouco inércia e autoprostração, como no pensamento meditativo proposto pelo último Heidegger. ${ }^{8}$ A paciência consiste no “(...) olhar demorado sobre o objeto [Gegenstand], sem querer forçá-lo" (Adorno, 1995a, p. 19). . A paciência vincula-se à negatividade do pensamento que resiste à qualquer tentativa de identificação com o objeto.

Há um duplo movimento presente na noção de paciência: ela se refere à forma como o pensamento filosófico se dedica ao mundo objetivo, sem nele diluir-se; e se dirige ao autozelo do próprio pensamento, a fim de preservar o seu potencial crítico.

A criticidade do pensar filosófico não visa apenas ao existente e sua representação na consciência, mas também ao próprio pensamento. A este cabe impor resistência, opondo-se à ruína da razão e à difamação do esclarecimento tout court. Resistir ao previamente pensado e não nadar a favor da corrente é, de acordo com Adorno, a característica e a força do pensamento filosófico.

Dessa forma, Adorno considera imensamente progressista a distinção entre teoria e prática: "O dogma da unidade entre teoria e práxis é, em oposição à doutrina a que se reporta, adialética: ele capta simples identidade ali onde só a contradição tem chance de ser frutífera" (Adorno, 1995b, p. 227). Para ele, teoria e prática não são de imediato as mesmas, nem distintas em absoluto. A prática é fonte da teoria; 
nesse sentido, o pensamento tem uma determinação social, mas, ao mesmo tempo, também é determinado de forma imanente: "Embora a teoria não possa ser arrancada do conjunto do processo social, também tem independência dentro do mesmo; ela não é somente meio do todo, mas também momento; não fosse assim, não seria capaz de resistir ao fascínio do todo" (Adorno, 1995b, p. 227).

Em razão dessa negatividade, o pensamento converte-se em força produtiva prática e, apenas assim, pode-se afirmar que não há pensamento sem telos prático. Portanto, a força de resistência do pensamento apresenta-se quando este plenifica a sua vocação negativa, sendo concebido fora do esquema da sua imediata aplicação:

Sempre que alcança algo importante, o pensamento produz um impulso prático, mesmo que oculto a ele. Só pensa quem não se limita a aceitar passivamente o desde sempre dado (...). Motivos dessa índole ainda atuam, talvez com maior força justo quando nenhum ensejo prático estiver imediatamente tematizado. (Idem, ibid., p. 210)

É possível afirmar que a Teoria Crítica, tal como Adorno a concebe, afirma sua negatividade no momento em que resiste ao insistente processo de fetichização da razão, ou seja, da onipresença da razão instrumental que ganha sua versão filosófica no pragmatismo.

Essa postura dilui qualquer perspectiva de fatalidade autodestrutiva da razão ou mesmo de completo determinismo da indústria cultural. É nesse sentido que Adorno aposta no potencial emancipatório da razão. Juntamente com Horkheimer, ele amplia e problematiza o conceito kantiano de esclarecimento e se pergunta como a humanidade, dominada pelo esclarecimento, submerge em uma catástrofe geral. Em outras palavras, "Por que a humanidade, em vez de entrar em estado verdadeiramente humano, está se afundando em uma espécie de barbárie?” (Adorno \& Horkheimer, 1985, p. 11).

Adorno e Horkheimer entendem, tal como Kant, que a liberdade na sociedade está ligada ao pensamento esclarecedor, mas reconhecem que

(...) o próprio conceito desse pensamento, tanto quanto as formas históricas concretas, as instituições da sociedade com as quais está entrelaçado, contêm o germe para a regressão que hoje tem lugar por toda parte (...). Abandonando a seus inimigos a reflexão sobre o elemento destrutivo do progresso, o 
pensamento cegamente pragmatizado perde seu caráter superador e, por isso, também sua relação com a verdade. $\mathrm{O}$ esclarecimento sela seu destino quando não reflete sobre esse elemento regressivo que ele próprio possui. (Adorno \& Horkheimer, 1985, p. 13)

Nesse sentido, ganha densidade a expressão dialética do esclarecimento como uma indicação de que os autores "(...) não desejavam jogar o bebê com a água do banho, mas simplesmente mostrar a ambigüidade da Aufklärung" (Wiggershaus, 2003, p. 357). A saída delineada implica um conceito positivo de esclarecimento, ou seja, este deve tomar consciência de si mesmo. Por isso, a cultura só pode sobreviver pela auto-reflexão crítica sobre aquilo em que ela se converteu - semicultura (Adorno, 1992). Nesse caminho, como visto, o exercício filosófico tem uma contribuição significativa.

\section{A vitalidade e atualidade da reflexão de Adorno}

A questão norteadora deste artigo é até que ponto a crítica de Adorno ao pragmatismo, dirigida em especial a Dewey, possui vitalidade e atualidade, ou seja, pode contribuir para a crítica da versão contemporânea dessa corrente filosófica. Esta indagação é pertinente, pois não são poucas as diferenças entre os primeiros e os atuais pragmatistas, cujo expoente principal é, sem dúvida, Rorty.

Além das diferenças entre o pragmatismo de Dewey e o de Rorty, pode-se ainda argumentar que a sociedade atual não é a mesma daquela enfocada por Adorno. Dessa forma, estariam suas reflexões obsoletas?

Ora, parece estar claro que, com o aprimoramento das formas de fetichização, é com uma sociedade capitalista altamente administrada que continuamos a lidar. As análises adornianas, apesar de repousarem sobre os processos sociais e as características que o capitalismo assumia em meados do século XX, apresentam-se provocativas, pois podem compor a crítica do pragmatismo, visto como uma tradição que se atualiza e se perpetua ao sabor de mudanças do próprio capitalismo.

Por isso, apesar das diferenças entre as posições de Dewey e Rorty, o que nos parece fecundo é conceber o pragmatismo como uma tradição. Isso significa considerá-lo uma corrente filosófica que possui diversas formas discursivas, que, por sua vez, articulam-se a um núcleo comum: a corrosão da teoria pela prática, entendida em seu caráter 
imediato; e o esvaziamento da relação entre verdade e mundo objetivo por meio do privilégio da eficácia.

A vitalidade da reflexão adorniana deve-se ao fato de se dirigir a esse núcleo da tradição pragmática. Adorno denuncia como, sob o modelo de uma sociedade administrada, a formação cultural se converte em semiformação, em cultura danificada. A partir do instrumentalismo burguês, dissemina-se uma ambiência ideológica impregnada do espírito pragmático que, ao instaurar a racionalidade do sempre-igual na relação sujeito e objeto, teoria e prática, alimenta o fenômeno descrito por Adorno como aversão à teoria. Configuram-se, assim, facetas da miséria da formação cultural contemporânea - a atrofia do pensar autônomo e a indigência da prática:

Essa é uma dialética desesperada: do fascínio que a práxis impõe aos homens não é possível escapar senão através da práxis, ela, porém, ao mesmo tempo - apática, estreita, carente de espírito -, contribui enquanto tal para reforçar esse fascínio. A mais recente aversão à teoria, que é a sua medula, faz disso um programa. (Adorno, 1995b, p. 207)

É nesse sentido que, em alusão ao filme Fahrenheit 451, Ramosde-Oliveira (1998) destaca que, nas atuais relações sociais, não é necessário destruir os livros se as gerações, sem disso ter consciência clara, são desensinadas da prática da leitura crítica e se submetem à lógica imediata da troca e do consumo.

A sociedade capitalista atrofia o pensar autônomo, mas, contraditoriamente, cria a possibilidade de um pensamento de resistência. Como lembra Adorno (1995b, p. 217), "nada no mundo administrado funciona sem rupturas". Mas aqui não se trata de qualquer pensamento, e sim daquele que se guia pela paciência, pelo amor e não abre mão de seu referente objetivo e da validade objetiva da verdade. Um pensamento que apreende a contradição do Esclarecimento e se opõe à ruína da razão: "A resistência que o pensar filosófico poderia opor à ruína da razão consistiria em (...) mergulhar nos conteúdos objetivos para perceber neles e não por cima deles o conteúdo de verdade" (Adorno, 1995a, p. 25).

A denúncia do recuo da teoria nas pesquisas educacionais e da vigência de uma utopia pedagógica praticista (Moraes, 2001), a crítica à desintelectualização do professor (Shiroma, 2003), à ideologia das 
competências, ao modelo de professor reflexivo (Arce, 2001) e à desvalorização do conhecimento escolar (Duarte, 2000) compõem esforços analíticos de constituição de uma agenda de luta e resistência, no campo educacional, aos ditames pragmáticos do capitalismo contemporâneo. Por mais peculiares que sejam as fundamentações teóricas dessas críticas, em vários aspectos, elas se entrecruzam com reflexões que a filosofia de Adorno pode inspirar de tal forma que não é forçoso afirmar que a sua contribuição pode compor essa agenda de luta.

A partir de Adorno, somos desafiados a compreender que a força da teoria e da filosofia consiste em não se curvar diante do apelo da pseudo-atividade e em manter o seu caráter de negatividade diante da força avassaladora da reificação. Somos convidados a perceber que a experiência reflexiva autêntica, criadora e criativa, no/sobre o trabalho educativo, não pode se desviar desse pensamento não eficaz, inútil: “(...) é no olhar para o desviante, no ódio à banalidade, na busca do que ainda não está gasto, do que ainda não foi capturado pelo esquema conceitual geral, que reside a derradeira chance do pensamento" (Adorno, 1993, p. 58). Isso significa assumirmos, enfim, aquilo que o capitão Beatty, do romance Fahrenheit 451, julgou ser necessário evitar e chamou curiosamente de $o$ caminho da melancolia.

\section{Recebido em abril de 2006 e aprovado em julho de 2007.}

\section{Notas}

1. Sobre esse fenômeno, Chartier (1999, p. 23) afirma que: "A cultura escrita é inseparável dos gestos violentos que a reprimem. Antes mesmo que fosse reconhecido o direito do autor sobre sua obra, a primeira afirmação de sua identidade esteve ligada à censura e à interdição dos textos tidos como subversivos pelas autoridades religiosas ou políticas (...). As perseguições são como que o reverso das proteções, privilégios, recompensas ou pensões concedidas pelos poderes eclesiásticos e pelos príncipes. $\mathrm{O}$ espetáculo público do castigo inverte a cena da dedicatória. A fogueira em que são lançados os maus livros constitui a figura invertida da biblioteca encarregada de proteger e preservar o patrimônio textual. Dos autos-de-fé da Inquisição às obras queimadas pelos nazis, a pulsão de destruição obcecou por muito tempo os poderes opressores, destruindo os livros e, com freqüência seus autores, pensavam erradicar para sempre suas idéias. A força do escrito é ter tornado tragicamente derrisória esta vontade".

2. No romance, a sociedade é altamente administrada pelo aparato militar - o corpo de bombeiros. A televisão é o principal mass media. Antes de conhecer Clarisse, o protagonista Montag amava a profissão de bombeiro, cuja função era queimar livros (a uma temperatura de $451^{\circ}$ Fahrenheit) e tudo relacionado à leitura. Após encontros fortuitos com Clarisse, Montag passa a suspeitar de sua própria felicidade, põe em xeque seu casamento, questiona os valores da sua profissão e se rebela contra seus superiores hierárquicos. 
3. Para Rorty (1994, p. 368), “(...) contato com a realidade (uma relação causal, não-intencional, não-relativa-a-descrição) com lidar com a realidade (descrever, explicar, predizer e modificá-la - tudo coisas que fazemos sob descrições)".

4. O termo alemão Bildung pode ser traduzido por: "(1) formar, conformar, configurar, modelar, dar forma, formar-se, a figura do aspecto; (2) formação espiritual e interna, aprimoramento, ser interior e espiritualmente bem formado, ligação de múltiplos conhecimentos por meio do gosto, juízo, senso de valor, graça, tato, bondade de coração; nesse segundo sentido, o termo pode também significar cultivo espiritual, cultura, boa formação" (Giacóia Jr., 2004, p. 1).

5. Em alemão, o termo halb indica meio, metade, semi. A tradução de Halbbildung por semiformação/semicultura foi privilegiada, neste artigo, em contraposição ao termo pseudoformação.

6. No mundo administrado, observam-se a fetichização da técnica, a coisificação do humano, portanto, a espoliação das relações humanas. Para Adorno, a semiformação é o espírito conquistado pelo caráter de fetiche da mercadoria, é a forma dominante da consciência atual (Ruschel, 1995, p. 240). Mundo administrado é a sociedade cujos gerentes e engenheiros de produção do capital tendem a transferir a prática de controle adotada nas empresas para a realidade social como um todo. A marca registrada desta prática pode ser ilustrada na atuação da indústria cultural.

7. Sobre indústria cultural e esquematismo, ver Duarte $(2005,2003)$.

8. Aqui, Adorno volta-se contra a noção heideggeriana (Heidegger, s/d) de meditação que, apesar de conter a crítica ao pensamento planejador e calculista e de denunciar a indigência do pensar, está vinculada às noçôes de enraizamento à terra natal e abertura ao mistério do Ser.

9. Adorno contraria Kant, pois, para este filósofo, a razão deve enfrentar a natureza "como um juiz que, no exercício de sua função, compele as testemunhas a responder às perguntas propostas por ele" (Kant, 1987, bxiii). A razão, segundo Kant (1987), procura na natureza o que ela ali depositou.

\section{Referências bibliográficas}

ADORNO, T.W. Teoria da semicultura. Trad. de Newton Ramos-deOliveira. Araraquara: UNESP, 1992. (mimeo.).

ADORNO, T.W. Minima moralia. 2. ed. São Paulo: Ática, 1993.

ADORNO, T.W. Observaçóes sobre o pensamento filosófico. In: ADORNO, T.W. Palavras e sinais: modelos críticos 2. Petrópolis: Vozes, 1995a. p. $15-25$.

ADORNO, T.W. Notas marginais sobre teoria e práxis. In: ADORNO, T.W. Palavras e sinais: modelos críticos 2. Petrópolis: Vozes, 1995 b. p. 202-229.

ADORNO, T.W. Educação após Auschwitz. In: Adorno, T.W. Educação e emancipação. Rio de Janeiro: Paz \& Terra, 1995c. p. 119-138. 
Aversão à teoria e indigência da prática: crítica a partir da filosofia de Adorno

ADORNO, T.W. Tempo livre. In: Adorno, T.W. Indústria cultural e sociedade. São Paulo: Paz \& Terra, 2002. p. 112-127.

ADORNO, T.W.; HORKHEIMER, M. Dialética do esclarecimento: fragmentos filosóficos. Rio de Janeiro: Zahar, 1985.

ADORNO, T.W.; HORKHEIMER, M. Indústria cultural: o iluminismo como mistificação das massas. In: AdORno, T.W. Indústria cultural e sociedade. São Paulo: Paz \& Terra, 2002. p. 7-80.

ALVES, G. Do "novo sindicalismo" à "concertação social”: ascensão (e crise) do sindicalismo no Brasil (1978-1998). Revista Sociologia Politica, Curitiba, n. 15, nov. 2000. Disponível em: <http://www.scielo.br/ scielo.php?pid=S0104-4782000000200008\&script=sci_ arttext\&tlng=pt>. Acesso em: 6 set. 2005.

ARAÚJO, O.R. Crise da política e dos partidos? Comunicação apresentada no Encontro Internacional "Civilização ou barbárie - desafios e problemas do mundo contemporâneo", 23-25 set. 2004, Serpa. Disponível em: <http://resistir.info/serpa/comunicacoes/octavio_r_araujo_ port.html>. Acesso em: 6 set. 2005.

ARCE, A. Compre o kit neoliberal para a educação e ganhe grátis os dez passos para se tornar um professor reflexivo. Educação \& Sociedade, Campinas, v. 22, n. 74, p. 251-283, abr. 2001.

BENJAMIN, C. O triunfo da razão cínica. Rebelion, 22 nov. 2003. Disponível em: <http://www.rebelion.org/brasil/031122benjamin.htm>. Acesso em: 6 set. 2005.

BRADBURY, R. Fahrenheit 451. São Paulo: Círculo do Livro, [s.d.].

CHARTIER, R. A aventura do livro: do leitor ao navegador. São Paulo: UNESP, 1999.

DEWEY, J. Democracy and education. 1916. Disponível em: <http:// www.ilt.columbia.edu/publications/dewey.html>. Acesso em: 6 set. 2005.

DUARTE, N. Vigotski e o "aprender a aprender". Campinas: Autores Associados, 2000.

DUARTE, R. Esquematismo e semiformação. Educação \& Sociedade, Campinas, v. 24, n. 83, p. 441-457, ago. 2003.

DUARTE, R. Teoria crítica da indústria cultural. Belo Horizonte: UFMG, 2003. 
GHIRALDELLI JR., P. A filosofia da educação do pragmatismo americano e o "Manifesto dos Pioneiros da Educação Nova": uma crítica a J.M. Azanha e D. Saviani. Filosofia, Sociedade \& Educação, Marília, v. 2, n. 2, p. 33-45. 1998.

GIACÓIA JR., O. A educação em Nietzsche e Adorno. In: COLÓQUIO INTERNACIONAL TEORIA CRÍTICA E EDUCAÇÃO, 2004., Piracicaba. Piracicaba: Unimer, 2004. 14p. (mimeo.).

HEIDEGGER, M. Serenidade. Lisboa: Instituto Piaget, [s.d.].

HENDLEY, B. Rorty revisitado. Filosofia, Sociedade \& Educação, Marília, v. 2, n. 2, p. 19-30. 1998.

KANT, I. Prefácio à 2a edição. In: KANT, I. Crítica da razão. 3. ed. São Paulo: Nova Cultural, 1987. p. 11-24.

MARX, K. O 18 Brumário de Luis Bonaparte. 4. ed. São Paulo: Nova Cultural, 1988.

MORAES, M.C.M. Recuo da teoria: dilemas da pesquisa em educação. Revista Portuguesa de Educação, Braga, v. 14, n. 1, 2001.

RAMOS-DE-OLIVEIRA, N. Reflexões sobre a educação danificada. In: Zuin, A.A.S. et al. (Org.). A educação danificada: contribuições à teoria crítica da educação. 2. ed. Petrópolis: Vozes; São Carlos: UfSCAR, 1998. p. 13-44.

RORTY, R A filosofia e o espelho da natureza. Rio de Janeiro: RelumeDumará, 1994.

RORTY, R. Ensaios sobre Heidegger e outros: escritos filosóficos 2. Rio de Janeiro: Relume-Dumará, 1999.

RUSCHEL, M.H. Glossário. In: Adorno, T.W. Palavras e sinais: modelos críticos 2. Petrópolis: Vozes, 1995. p. 237-253.

SHIROMA, E.O. O eufemismo da profissionalização. In: MoraEs, M.C.M. (Org.). Iluminismo às avessas. Rio de Janeiro: DP\&A, 2003. p. 61-79.

ZUIN, A.A.S. et al. Adorno: o poder educativo do pensamento crítico. Petrópolis: Vozes, 2000. 